\title{
Metabolic improvements following Roux- en-Y surgery assessed by solid meal test in subjects with short duration type 2 diabetes
}

Sudha S. Shankarr, Lori A. Mixson', Manu Chakravarthy ${ }^{1}$, Robin Chisholm², Anthony J. Acton², RoseMarie Jones ${ }^{3}$, Samer G. Mattar', Deborah L. Miller', Lea Petry ${ }^{4}$, Chan R. Beals' ${ }^{1}$, S. Aubrey Stoch', David E. Kelley ${ }^{1}$ and Robert V. Considine ${ }^{2^{*}}$

\begin{abstract}
Background: Glucose homeostasis improves within days following Roux-en-Y gastric bypass (RYGB) surgery. The dynamic metabolic response to caloric intake following RYGB has been assessed using liquid mixed meal tolerance tests (MMTT). Few studies have evaluated the glycemic and hormonal response to a solid mixed meal in subjects with diabetes prior to, and within the first month following RYGB.

Methods: Seventeen women with type 2 diabetes of less than 5 years duration participated. Fasting measures of glucose homeostasis, lipids and gut hormones were obtained pre- and post-surgery. MMTT utilizing a solid $4 \mathrm{oz}$ chocolate pudding performed pre-, 2 and 4 weeks post-surgery. Metabolic response to 4 and 2 oz MMTT assessed in five diabetic subjects not undergoing surgery.
\end{abstract}

Results: Significant reductions in fasting glucose and insulin at 3 days, and in fasting betatrophin, triglycerides and total cholesterol at 2 weeks post-surgery. Hepatic insulin clearance was greater at 3 days post-surgery. Subjects exhibited less hunger and greater feelings of fullness and satisfaction during the MMTT while consuming $52.9 \pm 6$. $5 \%$ and $51.0 \pm 6.5 \%$ of the meal at 2 and 4 weeks post-surgery respectively. At 2 weeks post-surgery, glucose and insulin response to MMTT were improved, with greater GLP-1 and PYY secretion. Improved response to solid MMTT not replicated by consumption of smaller pudding volume in diabetic non-surgical subjects.

Conclusions: With a test meal of size and composition representative of the routine diet of post-RYGB subjects, improved glycemic and gut hormone responses occur which cannot be replicated by reducing the size of the MMTT in diabetic subjects not undergoing surgery.

Trial registration: Clinical Trials.gov Identifier: NCT00957957 August 11, 2009.

Keywords: Roux-en-Y, Meal test, Gut hormones, Glucose, Insulin, C-peptide, GLP-1

\footnotetext{
* Correspondence: rconsidi@iu.edu

${ }^{2}$ Division of Endocrinology, Department of Medicine, Indiana University

School of Medicine, Indianapolis, IN, USA

Full list of author information is available at the end of the article
} 


\section{Background}

Bariatric surgery is an effective means of promoting significant long-lasting weight loss with concomitant improvement and/or resolution of diabetes and other associated co-morbidities. Of great interest is the observation that the Roux-en-Y gastric bypass (RYGB) procedure improves both fasting and dynamic measures of glucose homeostasis well before significant weight loss, resulting in the concept that RYGB surgery "cures diabetes" through mechanism(s) that are separable from weight loss itself [1-4]. As recently reviewed [5] possible weight lost independent mechanisms include the significant caloric restriction that reduces hepatic and pancreatic fat, the exclusion of nutrients from the duodenum, and the more rapid entry of nutrients into the distal small intestine with concomitant increased release of bile acids and gut hormones such as glucagon-like peptide 1 (GLP-1). While it is likely that no one mechanism is solely responsible for the acute improvements in glucose homeostasis, studies designed to test each mechanism independently often require post-surgery patients to engage in ingestive behavior that is not congruent with the intent of the surgery, such as consuming large caloric loads that match pre-surgery intake and which do not reflect the behavioral responses that occur postsurgery.

Mixed meal tolerance tests are often used to assess dynamic measures of glucose homeostasis because they are a physiologically relevant challenge that mimics the free living condition. In the bariatric literature many studies use commercially available liquid mixed meals with varied macronutrient content [6-10]. However, a liquid meal may not induce all the postprandial effects of solid meal consumption. For example, it has been argued that liquids are not as effective as solids in inducing cephalic phase responses in insulin or pancreatic polypeptide release [11, 12]. Liquids require less oral processing, have more rapid gastric-emptying and orocecal transit times $[13,14]$, and evoke lower expected satiation in nonbariatric subjects $[15,16]$. Cognitive manipulations of energy content and portion size can also significantly influence appetitive ratings and subsequent energy intake [17-19], with the perceived energy content of a food better predicting self-reported appetitive sensations than the true energy content [20,21]. Finally, it has been shown that the cognitive and sensory effects of food form alter ingestive behavior with oral-liquid and perceived gastric-liquid preloads eliciting greater postprandial hunger and lower fullness sensations, more rapid gastric-emptying and orocecal transit times, attenuated insulin and glucagon-like peptide 1 release, and lower ghrelin suppression than did responses after oral-solid and perceived gastric-solid treatments [22].
In the present study we utilized a solid mixed meal to examine the effect of RYGB surgery to alter the behavioral and metabolic response to caloric challenge at 2 and 4 weeks post-surgery in subjects with short duration type 2 diabetes. We also assessed acute changes in fasting glucose, lipids, betatrophin (as a marker of insulin resistance [23]) and gut hormones over the same time period. Our goal was to examine metabolic responses to caloric intake that mimicked real life conditions following RYGB surgery.

\section{Methods \\ Subjects}

Eighteen women scheduled for RYGB surgery were recruited, with 17 completing the full study. One subject was unable to complete all the required procedures due to post-operative complications immediately following surgery. Inclusion criteria were morbidly obese $\left(\mathrm{BMI}>35 \mathrm{~kg} / \mathrm{m}^{2}\right), 20-60$ years old, with documented type 2 diabetes (fasting plasma glucose $>126 \mathrm{mg} / \mathrm{dl}$ or $>200 \mathrm{mg} / \mathrm{dl} 2 \mathrm{~h}$ after $75 \mathrm{~g}$ OGTT), with total disease duration of 5 years or less at screening visit, and $\mathrm{HbA} 1 \mathrm{c} \leq 8.5 \%$. Diabetes was managed either by lifestyle modification (drug naïve), oral medications, or with insulin (maximum daily total dose $\leq 50$ units). Injectable GLP-1 analogs or oral DPP-4 inhibitors were discontinued at least 1 week prior to pre-surgery visit. At initial contact with the surgeons' office subjects were prescribed a low carbohydrate, whole food liver reduction diet to teach the better food choices that would be required following surgery.

Five subjects not scheduled for bariatric surgery (1 women and 4 men; BMI $39.4 \pm 2.7 \mathrm{~kg} / \mathrm{m}^{2}$; age $47 \pm 4 \mathrm{y}$ ) and meeting the inclusion criteria detailed above were recruited from the general population to assess the hormonal response to two different solid test meal (pudding) volumes. Three subjects were on metformin and two subjects were drug naïve at the time of testing.

All subjects gave informed consent and the protocol was approved by the Institutional Review Boards at Indiana University-Purdue University and Community Hospitals, Indianapolis, Indiana.

\section{Procedures}

Subjects participated in a baseline visit that occurred within the 2 weeks prior to their RYGB surgery, and visits at 3 days, 1,2 and 4 weeks post-surgery. Anthropometrics and fasting blood samples were obtained at all visits. Meal tolerance tests were performed presurgery and at 2 and 4 weeks post-surgery. The identical surgical procedure was performed by two surgeons and included a $1 \mathrm{oz}$ gastric pouch, $100 \mathrm{~cm}$ Roux and $50 \mathrm{~cm}$ biliopancreatic limb. 


\section{Mixed meal tolerance test (MMTT)}

A temporary indwelling catheter for venous access and sampling was placed and kept patent with saline. Bariatric subjects were provided a 4 oz pudding $(\sim 140 \mathrm{ml})$ consisting of $52.5 \mathrm{~g}$ whey protein, $25.0 \mathrm{~g}$ carbohydrate (11.1 g sugar) and $8.8 \mathrm{~g}$ fat. Subjects were instructed to consume the pudding within $15 \mathrm{~min}$, and to eat until they were full (subjects did not have to finish the pudding). Pudding consumed was determined by weigh back. The time zero blood sample was drawn and then the subjects began to eat. Subjects interrupted eating for $\sim 30-60 \mathrm{~s}$ for the blood draw at $10 \mathrm{~min}$. All samples were drawn by syringe and immediately placed into BD P700 inhibitor tubes kept on ice. Samples were spun at $4{ }^{\circ} \mathrm{C}$, aliquoted and frozen on dry ice within $10 \mathrm{~min}$ of the draw.

In the pilot effort to examine the metabolic effect of 4 versus $2 \mathrm{oz}$ of pudding, subjects not scheduled for bariatric surgery were randomly assigned in a crossover design to consume one volume of pudding at the first visit, and to consume the other volume at a second visit at least 1 week later. Blood samples were drawn and processed as above.

\section{Behavioral assessments}

Subjects rated their hunger, fullness, how much they could eat, satisfaction, nausea and energy level on horizontally oriented $100 \mathrm{~mm}$ Visual Analog Scales. Ratings were completed at baseline, 30 and 120 min during the meal test.

\section{Assays}

Glucose, triglycerides, cholesterol, apolipoproteins, insulin and C-peptide were measured using standard clinical analyzer methods on an ADVIA Centaur and Roche Modular system. Total GLP-1 was measured by radioimmunoassay (Millipore [Billerica, MA]; within CV = $22 \%$, between $\mathrm{CV}=23 \%$ at $20 \mathrm{pM}$ ), active GLP-1 by Meso Scale Electrochemiluminescence ([Rockville, MD]; within $\mathrm{CV}=9.3 \%$, between $\mathrm{CV}=3.6 \%$ at 0.7 and $1.3 \mathrm{pM}$ respectively), and pancreatic peptide YY (PYY) by ELISA (Millipore [Billerica, MA]; within $\mathrm{CV}=2.66 \%$, between $\mathrm{CV}=6.93 \%$ at $9.7 \mathrm{pM}$ ). For active GLP-1, values at the limit of detection were assigned a value of 0.65 , the lowest standard in the assay. Measures made on samples from the 5 subjects in the pilot effort on pudding volume were done in the Considine lab at Indiana University. Glucose was measured using a Randox Daytona Clinical Analyzer, with insulin (within $\mathrm{CV}=$ $3.1 \%$, between $\mathrm{CV}=6.0 \%$ at $8.0 \mu \mathrm{U} / \mathrm{ml}$ ) and c-peptide (within $\mathrm{CV}=3.4 \%$, between $\mathrm{CV}=9.3 \%$ at $0.4 \mathrm{ng} / \mathrm{ml}$ ) measured by radioimmunoassay (Millipore; Billerica, MA). Betatrophin was measured by ELISA (Phoenix Pharmaceuticals Inc [Burlingame, CA] ; within CV $=8.9 \%$ at $1 \mathrm{ng} / \mathrm{ml})$. HbA1c was measured by HPLC in the hospital lab as part of the subject's pre-surgery blood work.

\section{Statistical analysis}

Values are reported as mean \pm SEM. Insulinogenic index was calculated by dividing the increment in insulin or c-peptide during the first 30 postprandial minutes by the increment in glucose over the same period. Hepatic insulin clearance was estimated by the molar ratio of fasting C-peptide to insulin [24]. Total area under the curve (AUC) was calculated for all measures except gut peptides, for which incremental AUC was used. To assess the significance of changes over time, data were analyzed by repeated measures ANOVA followed by Tukey's multiple comparison test. Friedman test followed by Dunn's Multiple Comparison Test was used for groups with unequal variance. Analyses were conducted with GraphPad Prism 5. Statistical significance was set at $P<0.05$.

\section{Results}

Seventeen women (BMI $53.3 \pm 3.5 \mathrm{~kg} / \mathrm{m}^{2}$; age $45 \pm 10 \mathrm{y}$ ) with well-controlled type 2 diabetes (HbA1c $6.5 \pm 0.7 \%$ ) completed the study. The average duration of diabetes was $3.1 \pm 1.7$ years. Prior to surgery 14 subjects were taking antihyperglycemic therapy (7 on metformin, 1 on sulfonylurea, 3 on pioglitazone, 1 on GLP-1 analog, 1 on DPPIV inhibitor, and 1 on insulin), with 3 subjects not on any antihyperglycemic drugs. All subjects stopped their antihyperglycemic medications prior to surgery, and none required antihyperglycemic treatment following surgery.

Subjects lost weight over the course of the study, achieving a significant reduction beginning at 1 week postsurgery $(143.8 \pm 9.2,140.6 \pm 9.2,135.8 \pm 9.2,131.0 \pm 8.7 \mathrm{~kg}$, for pre-surgery, 1, 2, and 4 weeks respectively; $P<0.05$ ). As illustrated in Table 1, there were significant reductions in fasting glucose and insulin at 3 days post-surgery that were maintained over the course of the study. Fasting Cpeptide was significantly lower only at 3 days and 1 week post-surgery. Hepatic insulin clearance significantly increased beginning at day 3 . Triglycerides and total cholesterol were significantly lower at 2 weeks post-surgery. HDL cholesterol was significantly reduced beginning at 1 week post-surgery but there was no significant change in LDL cholesterol.

Fasting betatrophin was significantly reduced at 2 weeks post-surgery. There was no correlation between fasting betatrophin and fasting glucose, insulin or triglycerides at the pre- or post-surgery time points. There was also no relationship between the reduction in betatrophin at 2 weeks post-surgery and the reductions in glucose, insulin or triglycerides. 
Table 1 Fasting measures of glucose homeostasis and lipids

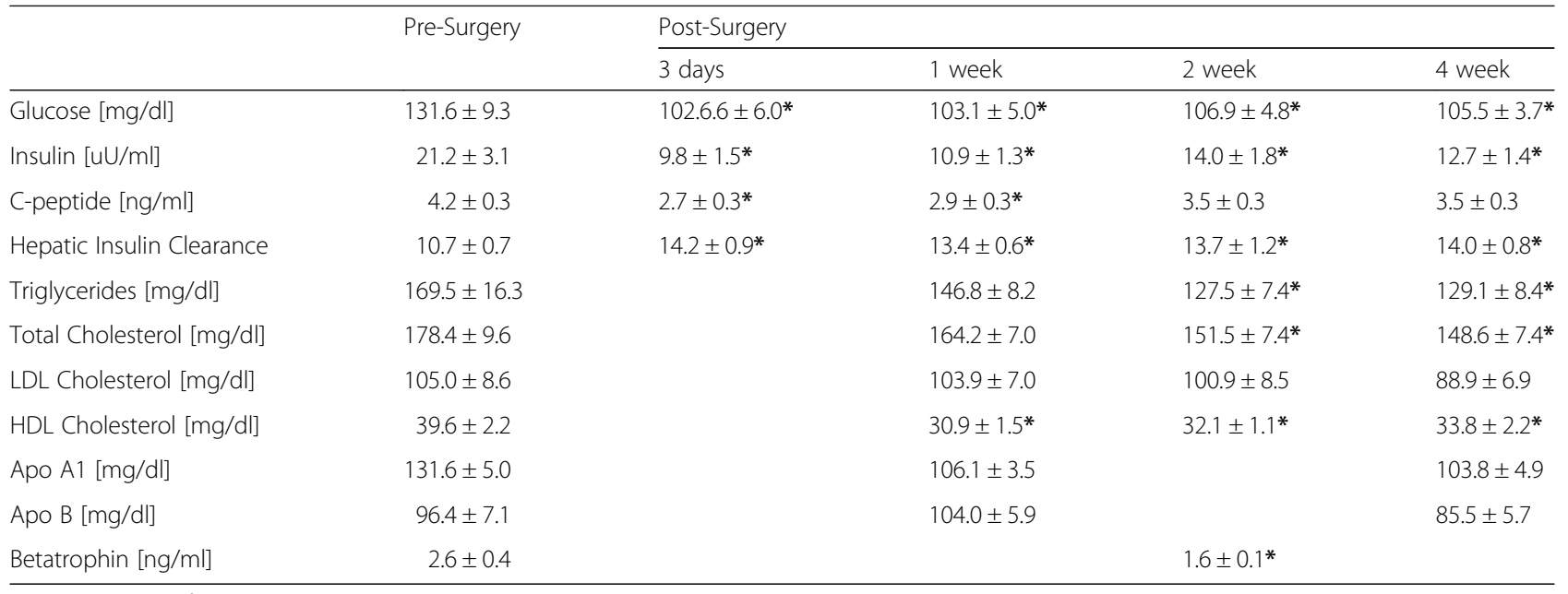

$* P<0.05$ compared to Pre-Surgery

\section{Subjective responses to meal challenge}

Subjects consumed $100 \%$ of the pudding provided prior to surgery, but only $52.9 \pm 6.5 \%$ and $51.0 \pm 6.5 \%$ of the pudding at 2 and 4 weeks post-surgery $(P<0.0001)$. As illustrated in Fig. 1, subjects began the meal test at 2 and 4 weeks post-surgery with significantly less hunger $(P=$ $0.014)$ and lower expectation of amount they could eat $(P=0.012)$, with greater feelings of fullness $(P=0.001)$ and satisfaction $(P=0.001)$, compared to pre-surgery. $\mathrm{AUC}_{\text {total }}$ for hunger and how much subjects could eat was significantly less, with that for fullness and satisfaction significantly greater at 2 and 4 weeks post-surgery
(Table 2). Nausea was low with energy level moderate and not different during the three meal tests.

\section{Hormonal responses to meal challenge}

Fasting glucose and insulin were significantly lower at the start of the 2 and 4 week post-surgery meal test (Table 1, Fig. 2). In contrast to pre-surgery, glucose and insulin exhibited a rapid rise that peaked at $30 \mathrm{~min}$, and returned to baseline by the end of the MMTT (Fig. 2). Fasting C-peptide did not differ across the three MMTT. However, during the two post-surgery MMTT, Cpeptide exhibited a more parabolic response with peak
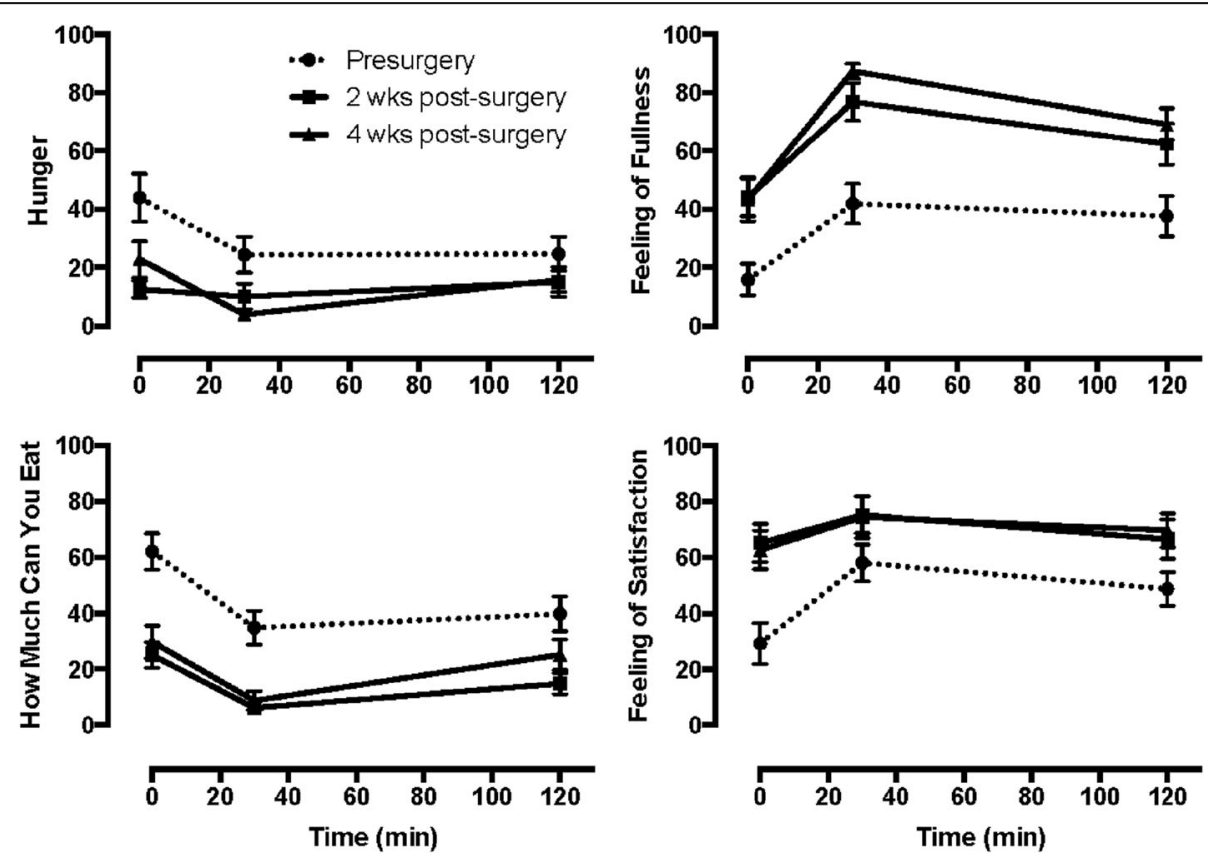

Fig. 1 Hunger and satiety ratings during the pre- and post-surgery solid meal test. Pre-surgery $A \cup C_{\text {total }}$ for each measure significantly different $(P<0.05)$ from that at 2 and 4 weeks post-surgery. See Table 2 
Table 2 AUC $_{\text {total }}$ for subjective responses during meal test at 2 and 4 weeks post-surgery

\begin{tabular}{llll}
\hline & $\begin{array}{l}\text { Pre- } \\
\text { Surgery }\end{array}$ & Post-Surgery & \\
\cline { 3 - 4 } & & 2 week & 4 week \\
\hline Hunger & $3231 \pm 596$ & $1474 \pm 469^{*}$ & $1293 \pm 283^{*}$ \\
How Much Can You Eat & $4812 \pm 524$ & $1411 \pm 273^{*}$ & $2104 \pm 1669^{*}$ \\
Feeling of Fullness & $4435 \pm 706$ & $8073 \pm 658^{*}$ & $9002 \pm 431^{*}$ \\
Feeling of Satisfaction & $6105 \pm 609$ & $8481 \pm 767^{*}$ & $8538 \pm 771^{*}$ \\
Nausea & $1218 \pm 511$ & $1771 \pm 613$ & $2078 \pm 649$ \\
Energy Level & $6324 \pm 716$ & $7313 \pm 515$ & $7142 \pm 505$ \\
\hline
\end{tabular}

${ }^{*} P<0.05$ compared to Pre-Surgery

at $30-60 \mathrm{~min}$, and values approaching baseline by $120 \mathrm{~min}$.

Insulinogenic index calculated using the change in insulin over the first $30 \mathrm{~min}$ was significantly lower at 2 weeks post-surgery $(0.65 \pm 0.22$ vs $0.22 \pm 0.03 \mathrm{nmol} /$ mmol; $P=0.0095)$ but not at 4 weeks $(0.27 \pm 0.04 \mathrm{nmol} /$ mmol). Insulinogenic index calculated using $\mathrm{C}$-peptide was also significantly lower at 2 weeks post-surgery $(1.94 \pm 0.68$ vs $0.73 \pm 0.09 \mathrm{nmol} / \mathrm{mmol} ; P=0.0209)$ but not at 4 weeks $(0.92 \pm 0.13 \mathrm{nmol} / \mathrm{mmol})$. $\mathrm{AUC}_{\text {total }}$ for glucose and insulin were significantly reduced at both 2 and 4 weeks post-surgery but C-peptide $\mathrm{AUC}_{\text {total }}$ was not significantly different across the study (Table 3 ). The ratio of AUC C-peptide/AUC glucose was not different across the study $(0.32 \pm 0.03,0.32 \pm 0.03,0.30 \pm$ $0.02 \mathrm{nmol} / \mathrm{mmol})$. The ratio of AUC insulin/AUC cpeptide was significantly reduced at 2 and 4 weeks post-surgery compared to the pre-surgery value $(8.9 \pm$ $0.5,6.3 \pm 0.4,5.80 .4$, respectively; $P<0.05$ ).

There was little release of active GLP-1 during the pre-surgery MMTT (Fig. 2). In contrast active GLP-1 increased significantly during the two post-surgery challenges, peaking at $30 \mathrm{~min}$ and returning to baseline by $120 \mathrm{~min}$. The incremental AUC for active GLP-1 was significantly greater at 2 and 4 weeks post-surgery as was $\mathrm{AUC}_{\mathrm{I}}$ for total GLP-1. Fasting PYY was significantly reduced at 1 week post-surgery $(35.3 \pm 3.2$ vs $23.9 \pm 2.0$ $\mathrm{pmol} / \mathrm{L} ; P=0.001)$. PYY exhibited a greater AUC during the MMTT only at 2 weeks post-surgery (Table 3 ).

\section{Effect of pudding volume on metabolic response to meal test}

To evaluate the effect of ingesting different pudding volumes on metabolic responses, five subjects with diabetes consumed 2 or $4 \mathrm{oz}$ of pudding on separate days. As shown in Fig. 3, glucose was elevated at the start of both meal tests, and exhibited a flat response curve similar to that of the bariatric subjects pre-surgery (Fig. 2). Also as observed for the pre-surgery subjects, insulin levels peaked at $60 \mathrm{~min}$ and did not return to baseline at 120 min with either pudding volume. C-peptide response was the same with both pudding volumes and did not exhibit a trend for return to baseline at $120 \mathrm{~min}$. Insulinogenic index calculated using the change in insulin $(0.50 \pm 0.26$ vs $0.48 \pm 0.14 \mathrm{nmol} / \mathrm{mmol})$ or C-peptide $(0.82 \pm 0.4$ vs $2.3 \pm 1.2 \mathrm{nmol} / \mathrm{mmol})$ was not significantly different by pudding volume. Glucose $\mathrm{AUC}_{\text {total }}$ was
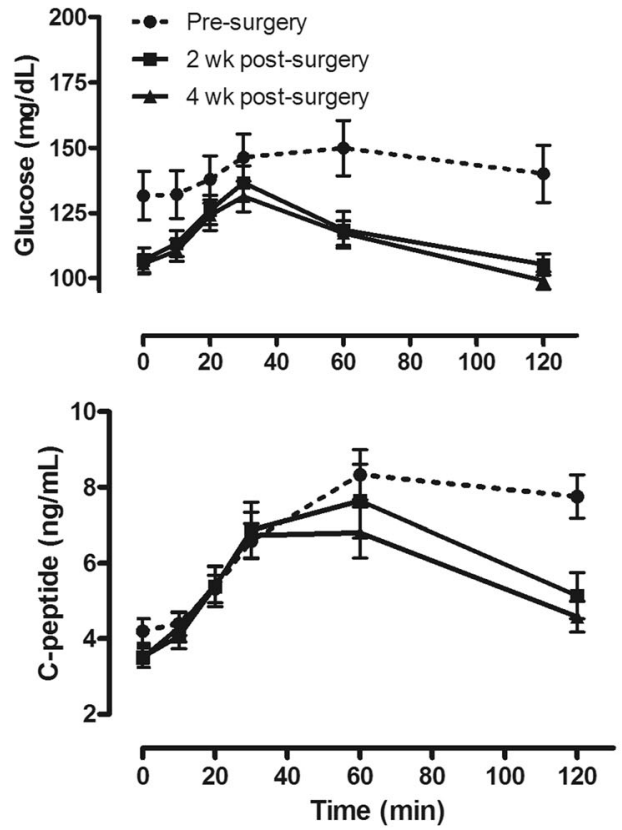
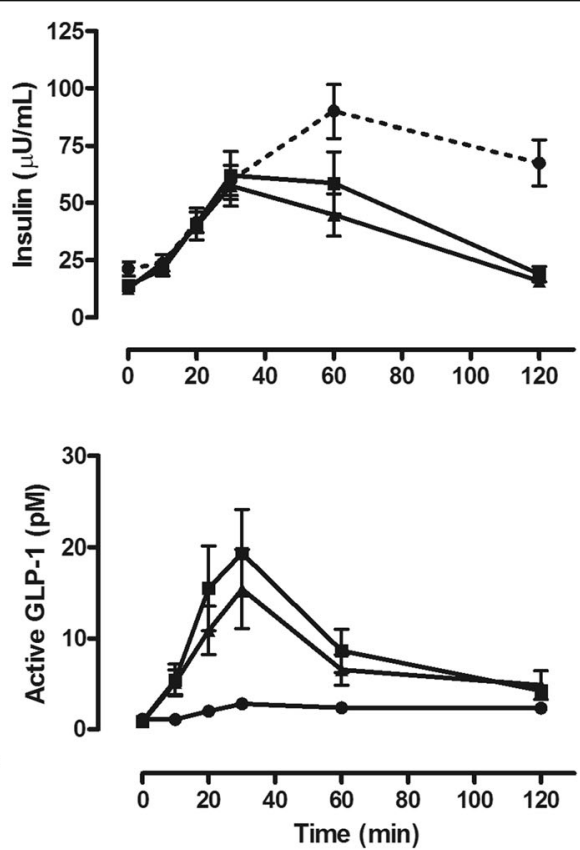

Fig. 2 Glycemic and hormonal response to solid meal test is improved following RYGB surgery. Pre-surgery AUC $C_{\text {total }}$ for glucose, insulin and active GLP-1 significantly different $(P<0.05)$ from that at 2 and 4 weeks post-surgery. See Table 3 
Table 3 AUC for glucose and hormone excursions during meal test at 2 and 4 weeks post-surgery

\begin{tabular}{llll}
\hline & Pre-Surgery & \multicolumn{2}{l}{ Post-Surgery } \\
\cline { 3 - 4 } & & 2 weeks & 4 weeks \\
\hline Glucose $[\mathrm{mg} / \mathrm{dl} \times \mathrm{min}]$ & $17,229 \pm 1199$ & $14,158 \pm 666^{*}$ & $13,776 \pm 509^{*}$ \\
Insulin [uU/ml x min] & $8027 \pm 943$ & $5142 \pm 914^{*}$ & $4354 \pm 701^{*}$ \\
C-peptide $[\mathrm{ng} / \mathrm{ml} \times \mathrm{min}]$ & $857 \pm 60$ & $748 \pm 81$ & $688 \pm 60$ \\
Active GLP-1 [pmol/L x min] & $137 \pm 29$ & $943 \pm 221^{*}$ & $778 \pm 196^{*}$ \\
Total GLP-1 [pmol/L x min] & $1034 \pm 317$ & $3717 \pm 668^{*}$ & $3428 \pm 668^{*}$ \\
PYY [pmol/L x min] & $196 \pm 160$ & $2874 \pm 643^{*}$ & $2058 \pm 544^{*}$ \\
\hline
\end{tabular}

$* P<0.05$ compared to Pre-Surgery

slightly less with consumption of $2 \mathrm{oz}$ of pudding compared to that following $4 \mathrm{oz}(19890 \pm 3918$ vs $20971 \pm$ $4144 \mathrm{mg} / \mathrm{dl} \times \mathrm{min}$ respectively; $P=0.016$ ), but remained comparable to that observed for the pre-surgery meal test. C-peptide $\mathrm{AUC}_{\text {total }}(415 \pm 36$ vs $443 \pm 71 \mathrm{ng} / \mathrm{ml} \mathrm{x}$ min) and insulin $\mathrm{AUC}_{\text {total }}(4153 \pm 515$ vs $7046 \pm 154 \mathrm{uU} /$ $\mathrm{ml} \times \mathrm{min}$ ) were not statistically different by pudding volume, although the lower insulin excursion with the $2 \mathrm{oz}$ meal suggests greater insulin clearance. There was no difference in $\mathrm{AUC}_{\text {total }}$ for hunger (5313 \pm 985 vs $3981 \pm$ 1349), how much subjects could eat $(7029 \pm 1639$ vs $6336 \pm 1680$ ), fullness $(5754 \pm 1553$ vs $6717 \pm 1149)$ or satisfaction (6972 \pm 1709 vs $9021 \pm 739)$ with consumption of 2 or $4 \mathrm{oz}$ of pudding. These data indicate that in the absence of surgery, consuming a meal of smaller volume does not improve the glycemic, insulin secretory or behavioral response to a test meal in obese subjects with diabetes.

\section{Discussion}

Subjects undergoing RYGB lost a modest amount of weight over the four weeks following surgery, and none needed to resume antihyperglycemic therapy following surgery. There were significant reductions in fasting glucose and insulin, with a significant increase in hepatic insulin clearance, as early as 3 days after surgery. Fasting betatrophin, triglycerides, total cholesterol, and HDL were significantly decreased post-surgery. Subjects exhibited less hunger, lower expectation of the amount of food they could eat, and greater feelings of fullness and satisfaction during the meal test following surgery, at which they consumed $\sim 50 \%$ less calories. Insulinogenic index and AUC for glucose and insulin were significantly lower at 2 weeks post-surgery. GLP-1 and PYY response to the meal was significantly increased post-surgery. The improvement in metabolic responses to the meal challenge following surgery could not be replicated by simply reducing meal volume in similar subjects who did not undergo surgery.

Acute reductions within the first post-operative week in fasting measures of glucose homeostasis support the

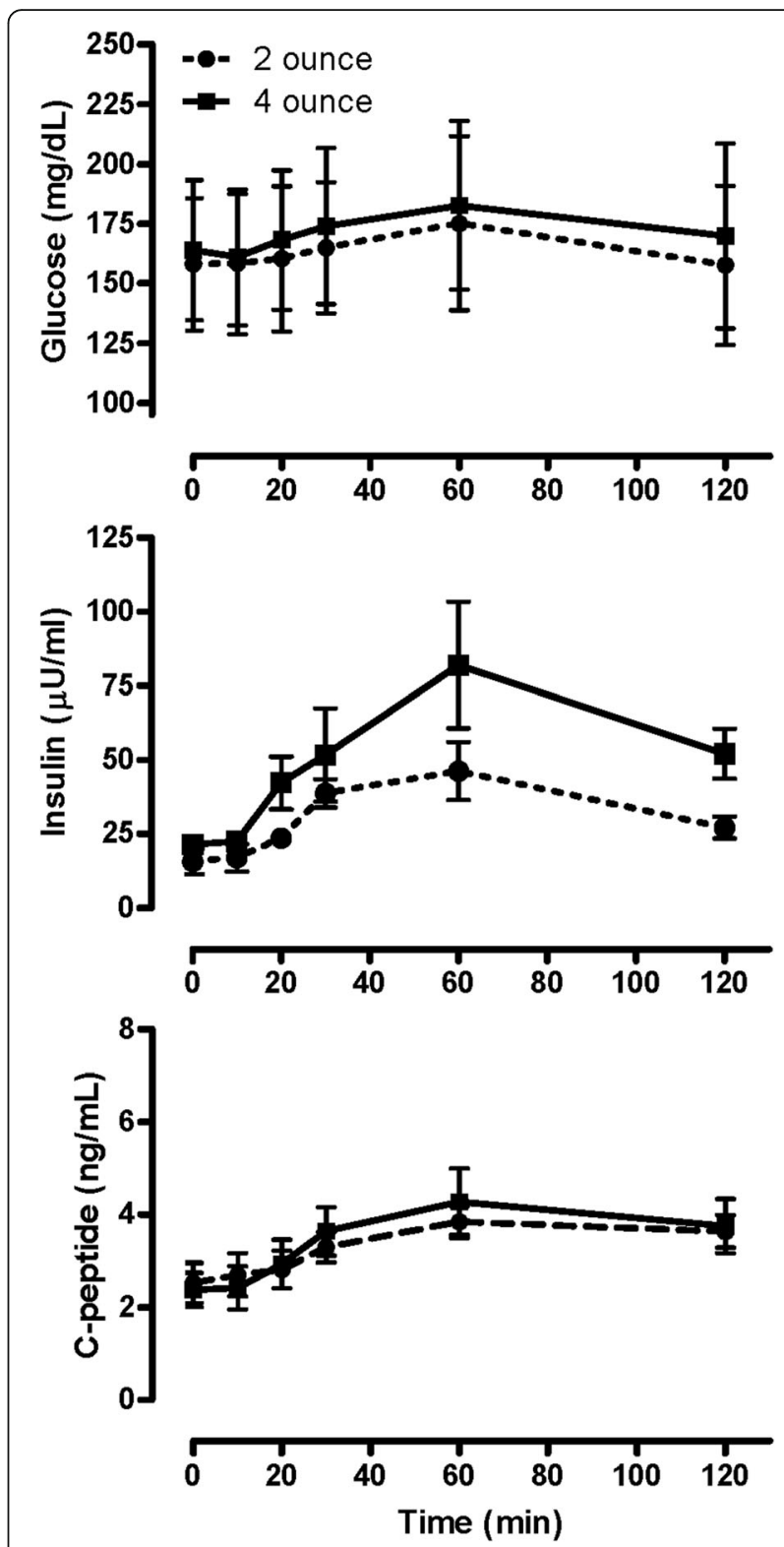

Fig. 3 Reductions in meal size do not normalize the glycemic and hormonal response to caloric challenge in subjects with type 2 diabetes. Glucose $A \cup C_{\text {total }}$ following consumption of $2 \mathrm{oz}$ of pudding lower than after $4 \mathrm{Oz}(P=0.016)$. Insulin and C-peptide $A \cup C_{\text {total }}$ not significantly different by pudding size

suggestion that bariatric surgery ameliorates diabetes [1-4] and this effect appears to be primarily driven by changes in hepatic metabolism. Increased hepatic insulin sensitivity, decreased hepatic glucose production and increased hepatic insulin clearance have all been observed within the first post-operative month [25-28], beginning as early as 1 week following surgery $[9,29]$. Several studies suggest that the improvement in hepatic metabolism is primarily due to the caloric restriction rather than the surgery per se $[27,30,31]$. However it is important to 
note that the degree of caloric restriction following RYGB surgery is difficult to achieve and maintain in the non-surgical population. Our data showing that subjects exhibited less hunger, lower expectation of the amount of food they could eat, and greater feelings of fullness and satisfaction in the fasting state support the efficacy of RYGB surgery to reduce caloric intake. It should be noted that the consumption of a low glycemic liver reduction diet prior to surgery was not sufficient to normalize hepatic metabolism to that attained following RYGB surgery.

Fasting triglycerides and total cholesterol significantly improved beginning at 2 weeks post-surgery, with a significant reduction in HDL at 1 week following surgery. A recent meta-analysis of data from 7815 subjects that underwent RYGB surgery found that, although heterogeneity among the studies included was high, triglycerides were significantly reduced by 3 months, total cholesterol and LDL by 1 month, and that HDL was unchanged until an increase at 1 year post-surgery [32]. The acute improvement in lipids observed here can likely be attributed to both reduced food intake, and reduced lipid absorption [33-35].

Betatrophin, or angiopoietin-like protein 8, is expressed in human liver and adipose tissue, is present in the circulation, and is involved in triglyceride metabolism [36]. Preclinical studies had suggested that betatrophin promoted $\beta$-cell proliferation [37] but this work has recently been retracted [38]. Betatrophin has also been suggested to be a marker of insulin resistance, although the nature of the relationship (positive or negative) is controversial, likely due to small differences in circulating protein across populations of different adiposity or diabetic status, and to differences in the commercially available human betatrophin assays [23]. In the current study we observed a small but significant reduction in fasting betatrophin at 2 weeks post-surgery, suggesting that betatrophin is increased in the diabetic state and reduced with normalization of insulin levels, although there was no correlation between betatrophin and fasting glucose, insulin or triglycerides. It is important to note that the assay used here employs an antibody targeted to the carboxy terminus of betatrophin, which has been shown to detect both full length and carboxy-terminal cleavage fragments of the protein [23]. Thus the reduction in betatrophin observed here is unlikely to be due to increased degradation of protein. A recent study has shown that insulin infusion increases adipocyte betatrophin expression in humans [39]. Thus it is possible that the reduction in circulating insulin following bariatric surgery decreases the signal for betatrophin production in adipose tissue.

In response to solid meal test following surgery, subjects experienced less hunger, lower expectation of the amount of food they could eat, and greater feelings of fullness and satisfaction, coincident with consumption of only $50 \%$ of the meal provided. Given that the volumes of liquid meal tests used in the bariatric literature range from 100 to more than $400 \mathrm{mls}$ [5-9 and others] it is note-worthy that subjects in the current study only comfortably consumed about $70 \mathrm{mls}$ following surgery. Factors that likely contributed to this outcome include the high protein content of the pudding, the slower more deliberate act of eating the pudding with a spoon, and individual perception that the pudding would be "filling". These important characteristics contribute to the success of bariatric surgery to limit caloric intake, and support dietary recommendations for this population to limit beverage intake to low or no calorie liquids [40].

Insulinogenic index, a dynamic measure of glucose homeostasis was significantly lower at 2 weeks postsurgery. Insulinogenic index has been shown to reflect meal size in normal weight subjects, doubling with a two fold increase in Kcal ingested [41]. We did not observe a difference in insulinogenic index in the non-surgical diabetic subjects consuming the two different pudding volumes, suggesting that the insulin secretory response was not properly responsive to glucose load in those subjects. Our observations suggest that following surgery the dynamic response to glucose ingestion was improved.

Greater post- than pre-surgery insulin and C-peptide excursions are generally observed when consuming large volume liquid mixed meals, resulting in an increase in post-surgery insulinogenic index (for example see $[8$, 10]). This observation has been interpreted to reflect an improved response to glucose ingestion, although such a response is unlikely to occur given the reduction in food intake per meal following surgery. Despite a $50 \%$ reduction in caloric stimulus post-surgery, we observed similar insulin/C-peptide release over the first $30 \mathrm{~min}$ preand post-surgery, suggesting that there was an increase in insulin and C-peptide release per caloric unit consumed, likely promoted by the significant increase in secretion of GLP-1.

Insulin AUC, but not that for C-peptide, was lower during the meal test post-surgery, indicating greater insulin clearance by the liver. Reductions in fasting and dynamic hyperinsulinema contribute to improved insulin sensitivity in muscle and adipose tissue, which has been documented to occur in parallel with weight loss [42]. Lower fasting glucose and smaller glucose response to caloric challenge contribute to improved insulin sensitivity via reduced glucotoxicity in insulin target tissues. Importantly, the improvements in glucose homeostasis observed here were not achieved by simply reducing the quantity and volume of test meal ingested, as shown in the diabetic subjects that did not undergo surgery. 
GLP-1 and PYY release during the meal test were greatly increased following surgery, as has been observed in a number of studies (reviewed in [43]). The enhanced secretion of GLP-1 and PYY resulting from the rapid transit of calories to the lower small intestine likely contributed to the reduction in food intake via their satiating effects on gut function and the central nervous system. The incretin effect of GLP-1 would be expected to result in greater insulin secretion during the meal test. Our observation that C-peptide release in response to the post-surgery meal test was unchanged, despite ingestion of half of the caloric load, suggests that GLP-1 did have an effect to promote greater insulin release, which was subsequently and efficiently cleared from the circulation by the liver.

A recent study in a small number of post-RYGB surgery subjects noted that a liquid meal induced greater increases in insulin and gut peptides than did a solid meal of similar caloric content [44]. This likely reflected the much faster absorption of calories provided by the liquid meal. We did not compare responses between solid and liquid meals as our intent, in contrast to that of Lee et al. [44], was not to determine a superior test method.

\section{Conclusions}

In summary we observed significant improvements in both fasting and dynamic metabolic measures following RYGB surgery in subjects with short duration diabetes. The use of a solid mixed meal test in this study permitted demonstration of improved glycemic responses to a meal challenge under the naturalistic conditions of reduced caloric intake experienced by bariatric surgery subjects. The metabolic improvements achieved with RYGB cannot be achieved by simply reducing food intake as demonstrated in non-surgical subjects.

\section{Abbreviations}

AUC: Area under the curve; GLP-1: Glucagon-like peptide 1; MMTT: Mixed meal tolerance test; PYY: Pancreatic polypeptide YY; RYGB: Roux-en-Y gastric bypass

\section{Acknowledgements}

The authors thank the subjects that participated in this study, as well as the nursing staff at Community Hospital North and IU Health North Hospital. Portions of this work were presented at the 72nd Annual Scientific Sessions of the American Diabetes Association, Philadelphia, PA.

\section{Funding}

The study was funded by Merck \& Co, Inc, Kenilworth, NJ. The funding organization was involved in the design and conduct of the study, the collection, management, analysis, and interpretation of the data, and the preparation, review, and approval of the manuscript.

\section{Availability of data and materials}

All datasets used and/or analysed during the current study are available in de-identified form from the corresponding author upon reasonable request.

\section{Authors' contributions}

SSS, LAM, MC, DM, LP, CRB, SAS and DEK all participated in conception and design, or planning of study. RC, AJA, RMJ, SM and RVC collected data. RMJ and SGM performed surgery. SSS, LAM, DEK and RVC analyzed the data. SSS, LAM, MC, DEK and RVC contributed to interpretation of results. SSS and RVC drafted of the manuscript. All authors reviewed and revised the manuscript for important intellectual content. All authors approved the final submitted version of manuscript.

\section{Competing interests}

SSS, LAM, MC, DM, LP, CRB, SAS, and DEK were employees of Merck Sharp \& Dohme Corp, a subsidiary of Merck \& Co., Inc., Kenilworth, NJ, at the time that work for this study was performed and may own stock or stock options with Merck. RVC received consulting fees from Merck \&Co, Inc. RC, AJA, RMJ, and SGM have no potential conflicts of interest regarding the content of this article.

\section{Ethics approval and consent to participate}

All subjects gave informed consent prior to participation in this study. The protocol was approved by the Institutional Review Boards at Indiana University-Purdue University and Community Hospitals, Indianapolis, Indiana.

\section{Author details}

${ }^{1}$ Experimental Medicine, Merck and Company, Rahway, NJ, USA. ${ }^{2}$ Division of Endocrinology, Department of Medicine, Indiana University School of Medicine, Indianapolis, IN, USA. ${ }^{3}$ Community Bariatric Services, Indianapolis, IN, USA. ${ }^{4}$ Department of Surgery, Oregon Health \& Science University, Portland, OR, USA.

Received: 1 November 2016 Accepted: 14 February 2017

Published online: 01 March 2017

\section{References}

1. Buchwald H, Avidor Y, Braunwald E, Jensen MD, Pories W, Fahrbach K, Schoelles K. Bariatric surgery: a systematic review and meta-analysis. JAMA. 2004;292:1724-37.

2. Sjostrom L. Review of the key results from the Swedish obese subjects (SOS) trial - a prospective controlled intervention study of bariatric surgery. Intern Med. 2013:273:219-34.

3. Pories WJ, Swanson MS, MacDonald KG, Long SB, Morris PG, Brown BM, et al. Who would have thought it? an operation proves to be the most effective therapy for adult-onset diabetes mellitus. Ann Surg. 1995;222: 339-50.

4. Pournaras DJ, Osborne A, Hawkins SC, Vincent RP, Mahon D, Ewings P, et al. Remission of type 2 diabetes after gastric bypass and banding: mechanisms and 2 year outcomes. Ann Surg. 2010:252:966-71.

5. Batterham RL, Cummings DE. Mechanisms of diabetes improvement following bariatric/metabolic surgery. Diabetes Care. 2016;39:893-901.

6. Korner J, Inabnet W, Conwell IM, Taveras C, Daud A, Olivero-Rivera L, et al. Differential effects of gastric bypass and banding on circulating gut hormone and leptin levels. Obesity (Silver Spring). 2006;14:1553-61.

7. Campos GM, Rabl C, Peeva S, Ciovica R, Rao M, Schwarz JM, Havel P, Schambelan M, Mulligan K. Improvement in peripheral glucose uptake after gastric bypass surgery is observed only after substantial weight loss has occurred and correlates with the magnitude of weight lost. J Gastrointest Surg. 2010;14:15-23.

8. Kashyap SR, Daud S, Kelly KR, Gastaldelli A, Win H, Brethauer S, Kirwan JP, Schauer PR. Acute effects of gastric bypass versus gastric restrictive surgery on beta-cell function and insulinotropic hormones in severely obese patients with type 2 diabetes. Int J Obes (Lond). 2010;34:462-71.

9. Bojsen-Møller KN, Dirksen C, Jørgensen NB, Jacobsen SH, Hansen DL, Worm D, Naver L, Kristiansen VB, Holst JJ, Madsbad S. Increased hepatic insulin clearance after Roux-en-Y gastric bypass. J Clin Endocrinol Metab. 2013;98: E1066-71

10. Martinussen C, Bojsen-Møller KN, Dirksen C, Jacobsen SH, Jørgensen NB, Kristiansen VB, Holst JJ, Madsbad S. Immediate enhancement of first-phase insulin secretion and unchanged glucose effectiveness in patients with type 2 diabetes after Roux-en-Y gastric bypass. Am J Physiol Endocrinol Metab. 2015;308:E535-44.

11. Teff KL, Devine J, Engelman K. Sweet taste: effect on cephalic phase insulin release in men. Physiol Behav. 1995;57:1089-95.

12. Teff KL. Cephalic phase pancreatic polypeptide responses to liquid and solid stimuli in humans. Physiol Behav. 2010;99:317-23. 
13. Glasbrenner B, Pieramico O, Brecht-Krauss D, Baur M, Malfertheiner P. Gastric emptying of solids and liquids in obesity. Clin Invest. 1993;71:542-6.

14. Hoad CL, Rayment P, Spiller RC, Marciani L, Alonso B de C, Traynor C, Mela DJ, Peters HP, Gowland PA. In vivo imaging of intragastric gelation and its effect on satiety in humans. J Nutr. 2004;134:2293-300.

15. DiMeglio DP, Mattes RD. Liquid versus solid carbohydrate: effects on food intake and body weight. Int J Obes Relat Metab Disord. 2000;24:794-800.

16. Brunstrom JM, Brown S, Hinton EC, Rogers PJ, Fay SH. Expected satiety changes hunger and fullness in the inter-meal interval. Appetite. 2011;56:310-5.

17. Schachter S, Gross LP. Manipulated time and eating behavior. J Pers Soc Psychol. 1968;10:98-106.

18. Wooley SC. Physiologic versus cognitive factors in short term food regulation in the obese and nonobese. Psychosom Med. 1972;34:62-8.

19. Wansink B, Painter JE, North J. Bottomless bowls: why visual cues of portion size may influence intake. Obes Res. 2005;13:93-100.

20. Wooley OW, Wooley SC, Dunham RB. Can calories be perceived and do they affect hunger in obese and nonobese humans? J Comp Physiol Psychol. 1972;80:250-8.

21. Crum AJ, Corbin WR, Brownell KD, Salovey P. Mind over milkshakes: mindsets, not just nutrients, determine ghrelin response. Health Psychol. 2011;30:424-9.

22. Cassady BA, Considine RV, Mattes RD. Beverage consumption, appetite, and energy intake: what did you expect? Am J Clin Nutr. 2012;95:587-93.

23. Fu Z, Abou-Samra AB, Zhang R. An explanation for recent discrepancies in levels of human circulating betatrophin. Diabetologia. 2014:57:2232-4.

24. Polonsky KS, Rubenstein AH. C-peptide as a measure of the secretion and hepatic extraction of insulin. Pitfalls and limitations. Diabetes. 1984;33:486-94.

25. Dunn JP, Abumrad NN, Breitman I, Marks-Shulman PA, Flynn CR, Jabbour K, Feurer ID, Tamboli RA. Hepatic and peripheral insulin sensitivity and diabetes remission at 1 month after Roux-en-Y gastric bypass surgery in patients randomized to omentectomy. Diabetes Care. 2012;35:137-42.

26. Nannipieri M, Baldi S, Mari A, Colligiani D, Guarino D, Camastra S, Barsotti E, Berta R, Moriconi D, Bellini R, Anselmino M, Ferrannini E. Roux-en-Y gastric bypass and sleeve gastrectomy: mechanisms of diabetes remission and role of gut hormones. J Clin Endocrinol Metab. 2013;98:4391-9.

27. Jackness C, Karmally W, Febres G, Conwell IM, Ahmed L, Bessler M, McMahon DJ, Korner J. Very low-calorie diet mimics the early beneficial effect of Roux-en-Y gastric bypass on insulin sensitivity and $\beta$-cell function in type 2 diabetic patients. Diabetes. 2013;62:3027-32.

28. Campos GM, Rabl C, Havel PJ, Rao M, Schwarz JM, Schambelan M, Mulligan K. Changes in post-prandial glucose and pancreatic hormones, and steadystate insulin and free fatty acids after gastric bypass surgery. Surg Obes Relat Dis. 2014;10:1-8.

29. Bojsen-Møller KN, Dirksen C, Jørgensen NB, Jacobsen SH, Serup AK, Albers PH, Hansen DL, Worm D, Naver L, Kristiansen VB, Wojtaszewski JF, Kiens B, Holst JJ, Richter EA, Madsbad S. Early enhancements of hepatic and later of peripheral insulin sensitivity combined with increased postprandial insulin secretion contribute to improved glycemic control after Roux-en-Y gastric bypass. Diabetes. 2014;63:1725-37.

30. Isbell JM, Tamboli RA, Hansen EN, Saliba J, Dunn JP, Phillips SE, MarksShulman PA, Abumrad NN. The importance of caloric restriction in the early improvements in insulin sensitivity after Roux-en-Y gastric bypass surgery. Diabetes Care. 2010;33:1438-42.

31. Lim EL, Hollingsworth KG, Aribisala BS, Chen MJ, Mathers JC, Taylor R. Reversal of type 2 diabetes: normalisation of beta cell function in association with decreased pancreas and liver triacylglycerol. Diabetologia. 2011;54:2506-14

32. Carswell KA, Belgaumkar AP, Amiel SA, Patel AG. A systematic review and meta-analysis of the effect of gastric bypass surgery on plasma lipid levels. Obes Surg. 2015;26:843-55.

33. Odstrcil EA, Martinez JG, Santa Ana CA, et al. The contribution of malabsorption to the reduction in net energy absorption after long-limb Roux-en-Y gastric bypass. Am J Clin Nutr. 2010;92:704-13.

34. Carswell KA, Vincent RP, Belgaumkar AP, et al. The effect of bariatric surgery on intestinal absorption and transit time. Obes Surg. 2014;24:796-805.

35. Kumar R, Lieske JC, Collazo-Clavell ML, et al. Fat malabsorption and increased intestinal oxalate absorption are common after Roux-en-Y gastric bypass surgery. Surgery. 2011;149:654-61.

36. Quagliarini F, Wang Y, Kozlitina J, et al. Atypical angiopoietin-like protein that regulates ANGPTL3. Proc Natl Acad Sci U S A. 2012:109:19751-6.
37. Yi P, Park J-S, Melton DA. Betatrophin: a hormone that controls pancreatic $\beta$ cell proliferation. Cell. 2013:153:747-58.

38. Yi P, Park J-S, Melton DA. Retraction notice to: betatrophin: a hormone that controls pancreatic $\beta$ cell proliferation. Cell. 2017;168:1-2.

39. Nidhina Haridas PA, Soronen J, Sädevirta S, Mysore R, Quagliarini F, Pasternack A, et al. Regulation of angiopoietin-like proteins (ANGPTLs) 3 and 8 by insulin. J Clin Endocrinol Metab. 2015;100:E1299-307.

40. Mechanick Jl, Kushner RF, Sugerman HJ, Gonzalez-Campoy JM, CollazoClavell ML, et al. American association of clinical endocrinologists; obesity society; American society for metabolic \& bariatric surgery. American association of clinical endocrinologists, the obesity society, and American society for metabolic \& bariatric surgery medical guidelines for clinical practice for the perioperative nutritional, metabolic, and nonsurgical support of the bariatric surgery patient. Obesity (Silver Spring). 2009;17 Suppl 1:S1-70.

41. Alsalim W, Omar B, Pacini G, Bizzotto R, Mari A, Ahrén B. Incretin and islet hormone responses to meals of increasing size in healthy subjects. J Clin Endocrinol Metab. 2015;100:561-8.

42. Svane MS, Bojsen-Møller KN, Madsbad S, Holst JJ. Updates in weight loss surgery and gastrointestinal peptides. Curr Opin Endocrinol Diabetes Obes. 2015;22:21-8.

43. Scott RV, Tan TM, Bloom SR. Can bayliss and starling gut hormones cure a worldwide pandemic? J Physiol. 2014;592(Pt 23):5153-67.

44. Lee CJ, Brown TT, Cheskin $\sqcup$, Choi P, Moran L, Peterson R, et al. Effects of meal composition on postprandial incretin, glucose and insulin responses after surgical and medical weight loss. Obesity Sci Pract. 2015;1:104-09.

\section{Submit your next manuscript to BioMed Central and we will help you at every step:}

- We accept pre-submission inquiries

- Our selector tool helps you to find the most relevant journal

- We provide round the clock customer support

- Convenient online submission

- Thorough peer review

- Inclusion in PubMed and all major indexing services

- Maximum visibility for your research

Submit your manuscript at www.biomedcentral.com/submit
) Biomed Central 